\title{
Gas Turbine Engine Starting Applicated on TV2-117 Turboshaft
}

\author{
Razvan Marius Catana \\ Gas Turbine Experimentation \\ Complex, RR\&DI for Gas Turbines \\ Comoti \\ Bucharest, Romania \\ razvan.catana@comoti.ro
}

\author{
Grigore Cican \\ Aerospace Sciences \\ "Elie Carafoli" Department \\ Politehnica University of Bucharest \\ Bucharest, Romania \\ grigore.cican@upb.ro
}

\author{
Gabriel Dediu \\ Gas Turbine Experimentation \\ Complex, RR\&DI for Gas Turbines \\ Comoti \\ Bucharest, Romania \\ gabriel.dediu@comoti.ro
}

\begin{abstract}
The paper presents the examination of two different types of engine starting configurations, applicated on TV2-117A turboshaft, running into the test bench. The first type of starting configuration is a normal starting, with the engine connected to the dynamometer which controls the free turbine speed by the dynamometer load. The second type of starting is a different one, the engine is not connected with the dynamometer, therefore it results that there is no control of the free turbine speed from the dynamometer, only from the engine but in particular conditions. To achieve the starting phase an instrumentation scheme is created, to control and monitor the engine, and a starting sequence with all the parameters, confirmations and commands that are involved into the starting phase. The engine starting is performed by the test bench operating system, composed of an acquisition system and a programmable controller, wherewith is running the starting sequence.
\end{abstract}

Keyword- turboshaf; starting; instrumentation scheme; graphic interface; monitoring parameters

\section{INTRODUCTION}

The starting and the testing of gas turbine engines will be performed each time the engine is overhauled [6], taken out of preservation, or each time the engine encounters a problem which affects its working parameters. There are some references about starting and testing procedures of turboshaft engines but only for the new generation of this type of engine $[1,2]$. The testing of gas turbine engines implies an automatic system in order to monitor the main parameters and to control the engine in time of running. For starting and testing older generation of turboshaft engines which are not equipped with electronic control units, it is necessary to create the instrumentation and the graphic interface in order to monitor and record the main and secondary parameters, confirmations and warnings which describe the engine operation. In this paper, a logical scheme for starting sequence of TV2-11A turboshaft engine, which will be run into a test bench will be realized. In one case the engine will be started in connection with the dynamometer at different loads, and in the other case the engine is not connected with the dynamometer which means the engine will start without any brake and any load. The TV2-117A [3], is a turboshaft engine with a free-turbine composed of two rotors, the rotor of the gas generator and the rotor of the free power turbine. The gas generator consists of nine stage axial compressor, of which four stator stages are with variable geometry, an annular combustion chamber and two stage axial turbines. The power turbine is also an axial turbine, consisting of two stages, which is controlled by a speed regulator. The free power turbine speed regulator maintains constant the free power turbine speed, by fuel control, in connection with the engine main fuel pump. In the starting phase the free power turbine speed regulator is a hydro mechanical speed controller that ensures the free power turbine not to over speed. In flight configuration, (Figure 1), the engine transfers power from the free turbine rotor through a drive train assembly to the main rotor blade 1 and to the tail rotor blade 6 , in the following way: the engine delivers power to the main gear box, by the main drive shaft 2 , to the main rotor blade 1 , also from the main gear box 2, by tail drive shaft 3 through an intermediate gear box 4 , and by a secondary tail drive shaft 5 , a part of power is delivered to the tail rotor blade 6 . All the drive gear assemblies develop a resistive torque who defines the idle speed of the free power turbine at the idle engine mode.

So in this case, on starting phase the engine starts with a mechanical load which is the resistive torque of the helicopter drive train assembly. In the idle mode [1], the engine develops maximum power around $\mathrm{P} \approx 60 \mathrm{~kW}$, at $\mathrm{NTP}=45 \pm 10 \%$ free power turbine speed and gas generator speed around $\mathrm{NGG}=$ $65 \pm 1 \%$. The rotor of the gas generator works at a maximum speed of $\mathrm{NGG}=21200 \mathrm{rpm}$, delivers an air flow rate around of $\mathrm{DA} \approx 7.5 \mathrm{~kg} / \mathrm{s}$, and makes an overall pressure ratio $\approx 6.5: 1$, at the maximum free power turbine speed of NTP $=12000 \mathrm{rpm}$.

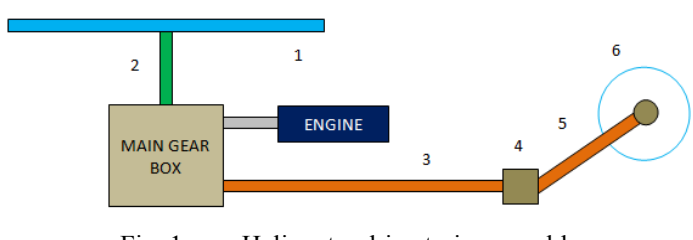

Fig. 1. Helicopter drive train assembly

\section{STARTING CONFIGURATION}

To execute a normal starting, into the test bench, the engine is connected to the dynamometer,(Figure 2), which is a brake for the free power turbine. To start the engine in the same 
conditions as on helicopter, from dynamometer it is demanded the resistive torque value of the drive train assembly. The dynamometer has the capability to demand any load to start the engine. If you demand a lower load, the engine will start with a higher speed of free turbine, or if you demand a higher load the engine will start with a lower speed of free power turbine. In this case the value of load, modifies the starting value of the free turbine speed.

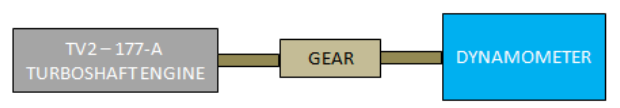

Fig. 2. Turboshaft starting configuration

To make an engine run into a normal starting configuration it is necessary to calculate the resistive torque, which is the value of demanded dynamometer load. To calculate the resistive starting torque the next equation is used [4].

$$
\mathrm{C}=\frac{30 \cdot \mathrm{P}}{\pi \cdot \mathrm{NTP}} \cong 100 \quad[\mathrm{Nm}]
$$

To execute the second type of starting, the engine is not connected with the dynamometer, so there is no brake for the free power turbine rotor, which means that the free turbine will produce a higher idle speed. In this case the control of the free turbine speed is made by free turbine speed regulator. If the free turbine speed exceeds $12000 \mathrm{rpm}$ then the free turbine regulator reduces the fuel flow to the combustion chamber, through the main fuel pump, which means a low idle of a gas generator. If the free turbine speed not exceeds more than $90 \%$ of 12000rpm, then the gas generator has a normal idle and the free turbine speed can be higher with $20 \%$ or $50 \%$ than the normal idle free turbine speed.

\section{ENGINE STARTUP PROCEDURE}

TV2-117A is a turboshaft engine which is not equipped with an engine control unit, and to perform an automatic start, into a test bench, it is required to have a control and acquisition system, which contain a programmable logic controller capable to execute the starting sequence inserted into the logic controller under a programming code. To achieve the starting sequence the main parameters and commands that will be instrumented to monitor the engine working are established [5]. TV2-117A engine has a standard instrumentation, (Figure 3), formed of main parameters as gas generator shaft speed NGG, inlet turbine temperature T3M, fuel flow DC, oil pressure PUMi, outlet oil temperature TUMe, vibrations VbM, and main commands of engine as starter, CMD3, ignition unit IGN, CMD4, starting fuel valves SE1-2, CMD5, start lever EM STOP, CMD2, and an external commands as fuel pump P_PC, CMD1. For a detailed monitoring it is instrumented the engine with additional parameters as air flow DA, free power turbine shaft speed NTP, compressor outlet static pressure P2s, and inlet fuel pressure PPC.

For execution of the engine starting general diagram of the operating system is presented, consisting of general engine instrumentation and an acquisition system, that are used for engine operation from a control panel located in the test bench control room. From the control panel the signal of commands is transmitted to the actual commands, which are the engine starting system components, and which are involved into the starting phase. The engine run starting procedure [7] contains the steps of the starting sequence, (Figure 4), which involves commands, confirmations and conditions that participate to the starting phase. There are a series of confirmations and warning lights reported to the engine parameters. The running program can execute a dry motoring, a wet motoring and an engine run. In this case only the engine run mode is showed.

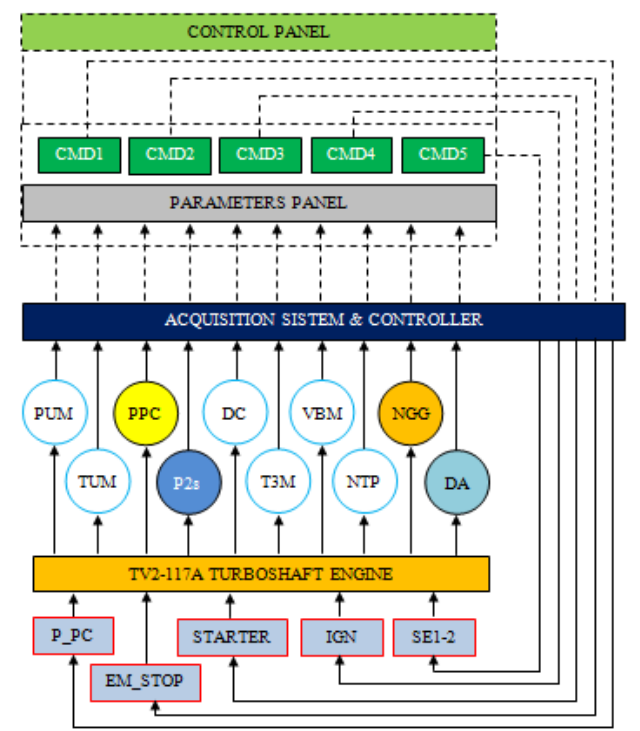

Fig. 3. TV2-117A Instrumentations and acquisition system

To perform an engine run starting, select the button dedicated to the engine run and the sequence will start automatically, in function of time or speed NGG parameter, or manual controlled. So the logical starting sequence of engine run begins with the initialisation of the commands IN-CMD, warning lights IN-LH, and a starting condition SPC of a series of parameters which confirms the engine is ready for starting. Engine run sequence starts with: select engine run SL3 in ON position then turn on the fuel pump, by acting the CMD1 command in $\mathrm{ON}$ position, check if fuel pressure increases and wait the fuel pressure to be above the minimum value. If the condition is satisfied, the warning light goes off and it opens the engine fuel shut off valve by moving the start lever and acting the CMD2 command in ON position, to allow the fuel to enter into the engine. If the start lever is in open position then a time t0r will start to be counted. At time t1r, it turns on the starter by acting the CMD3 command in ON position. At time $\mathrm{t} 2 \mathrm{r}$ the ignition is energized by acting the CMD4 command in $\mathrm{ON}$ position. With the starter in ON position the speed NGG begins to increase and when exceeds $17 \%$ it opens the starting fuel supply valves by acting the CMD5 command in ON position, to allow the fuel to enter into the engine fuel system and to be ignited into the combustion chamber. At the same time the speed NGG and oil pressure PUM have to increase until they exceed minimum values of the operations, the speed NGG must be higher than $60 \%$, PUM must be higher than 2 bar, 
and the inlet turbine temperature must be lower than $600^{\circ} \mathrm{C}$. If NGG speed, oil pressure PUM and inlet turbine temperature $\mathrm{T} 3 \mathrm{M}$, respect the condition then the engine continues to run and when the engine is on the stable idle speed, then it stops the starter, ignition and starting fuel supply valve by acting the CMD5, CMD4, CMD3 commands in OFF position, so in this way the engine is on idle mode. In idle mode the engine works for maximum five minutes, monitoring and recording the main parameters and then it stops the engine by acting the CMD2 command in OFF position. For the starting examinations an interface display was made to monitor in real time the engine parameters, confirmations and commands, to be viewed by the engine operator. The interface can be designed in different programs but in this case the interface it was designed into a dedicated engine running programming (Figures 4-5).

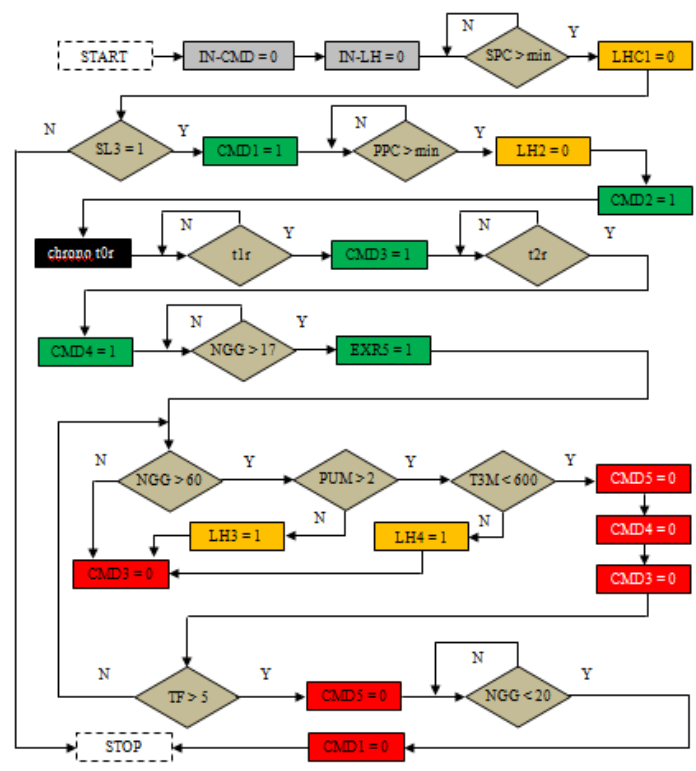

Fig. 4. The logical starting scheme

\section{SENSORS AND MESURING DEVICES}

To monitor the main parameters of the TV2-117 turboshaft, a series of sensors and transducers was mounted on the engine, as presented in Figure 6. For measuring the engine speed NGG, free turbine speed NTP, compressor discharge static pressure piCs, outlet engine oil temperature TUM, fuel flow DC, vibrations VBM, a tachogenerator is used, an inductive speed transducer, pressure transducers, Pt100 sensor, a fuel flow meter and accelerometers. For measuring of inlet turbine temperature $\mathrm{T} 3 \mathrm{M}$, the engine is equipped with 34 thermocouples.

\section{RESUlTS}

From TV2-117 turboshaft starting on the test bench was obtained a series of variation curves between some engine main parameters (Figures 9-16). The engine starting is performed and showed until idle mode. The engine runs are made in two configurations, normal starting, with minimum load (Figure 5), helicopter starting load (Figure 7), unusable starting, with no load and no connection with the dynamometer (Figure 8). In
Figure 5 is showed a normal starting with $5 \mathrm{Nm}$ torque value of dynamometer load. In all the cases the engine has a normal starting, the main parameters have small differences between them and only the major differences are in the values of the free turbine speed. For the unusable starting (Figure 8), the free turbine has no brake, so the free turbine speed exceeds $90 \%$ without limiting the engine idle.

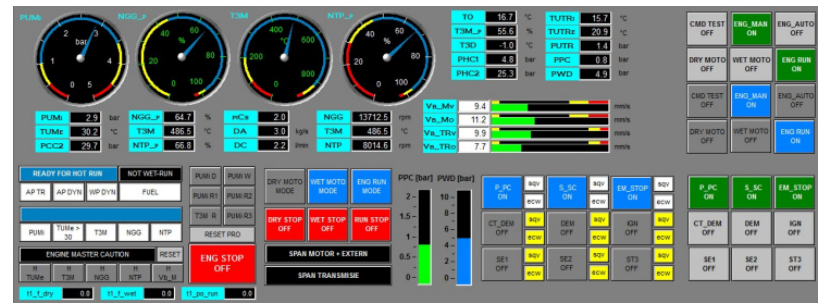

Fig. 5. Engine monitoring interface

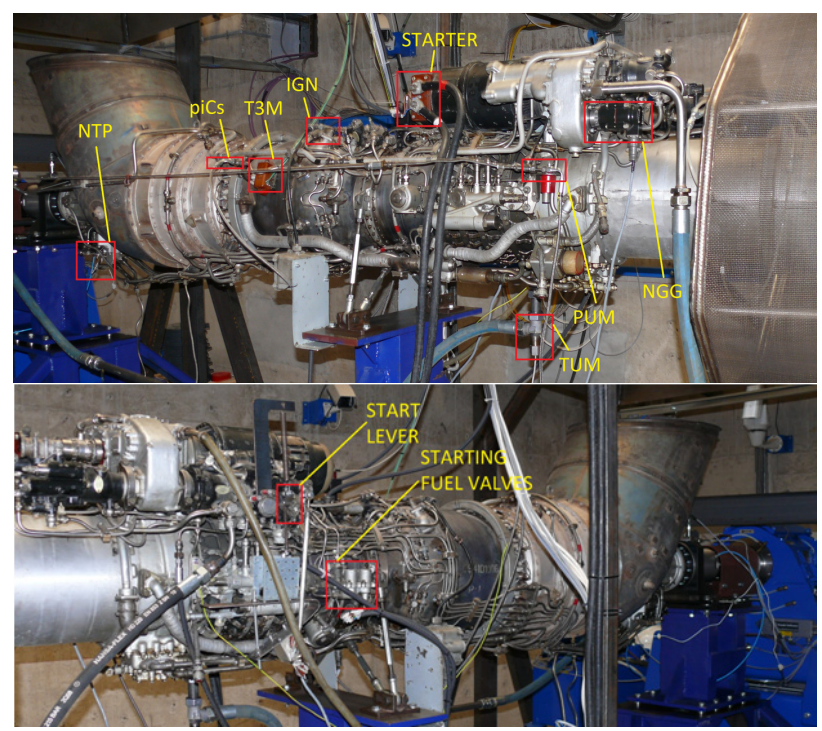

Fig. 6. Sensors and Measuring Devices for TV2-117 turboshaft engine

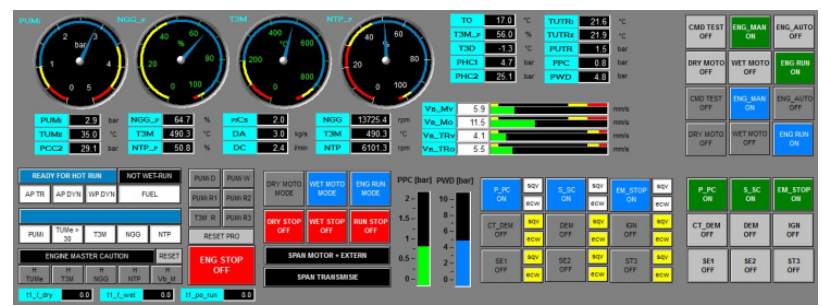

Fig. 7. Normal starting with the same helicopter starting load $\approx 100 \mathrm{Nm}$

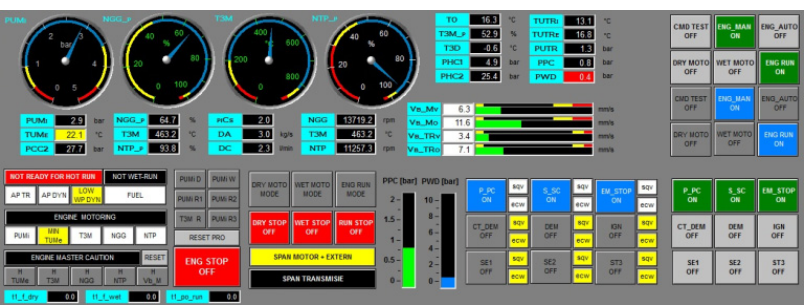

Fig. 8. Unusable starting with no load and no connection with the dynamometer 


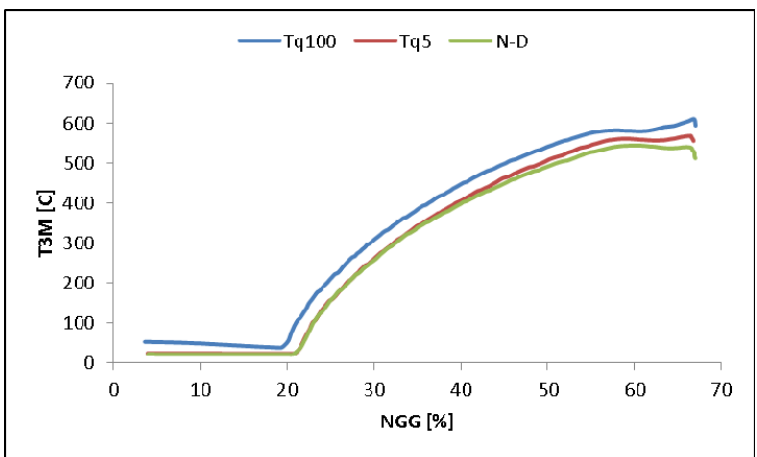

Fig. 9. Inlet Turbine Temperature variation with engine speed

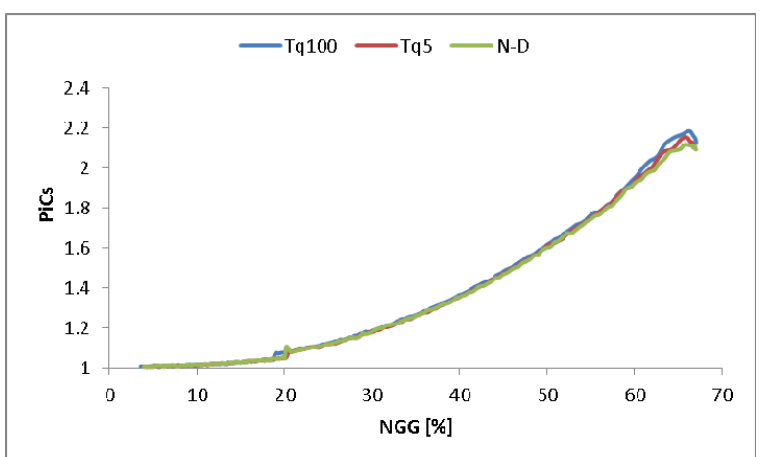

Fig. 10. Static overall pressure ratio variation with engine speed

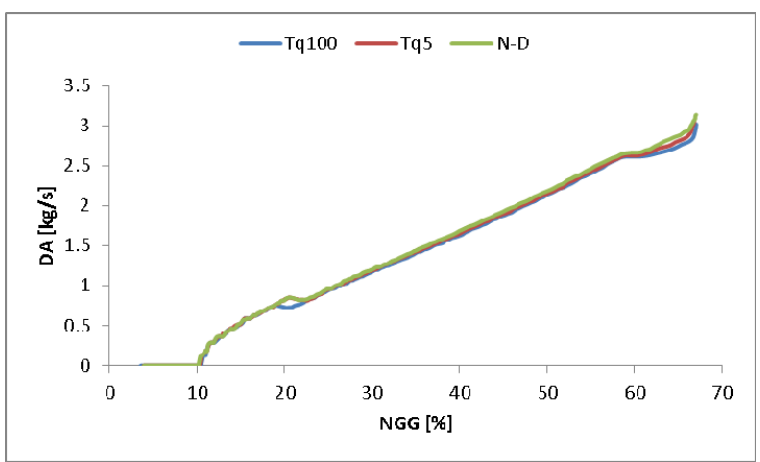

Fig. 11. Air flow variation with engine speed

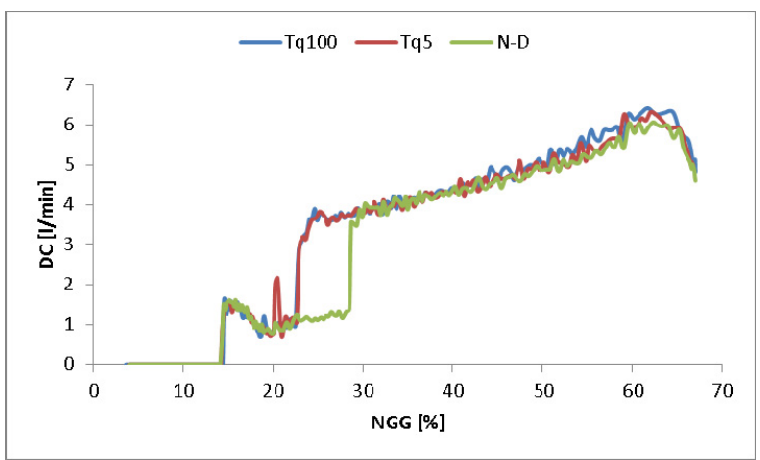

Fig. 12. Fuel flow variation with engine speed

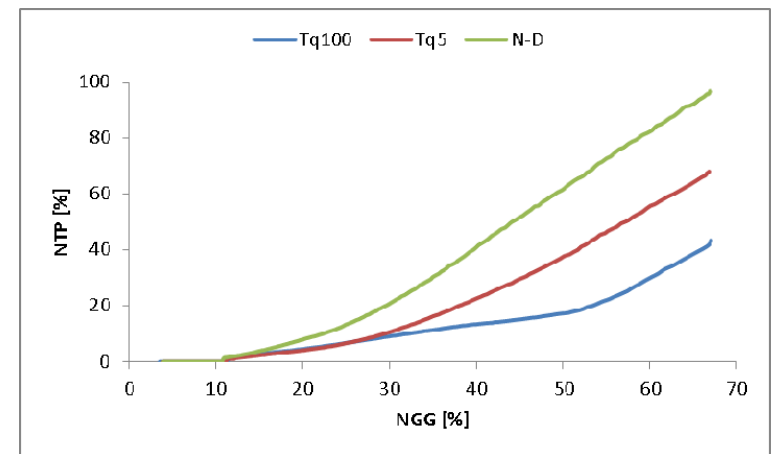

Fig. 13. Free turbine speed variation with engine speed

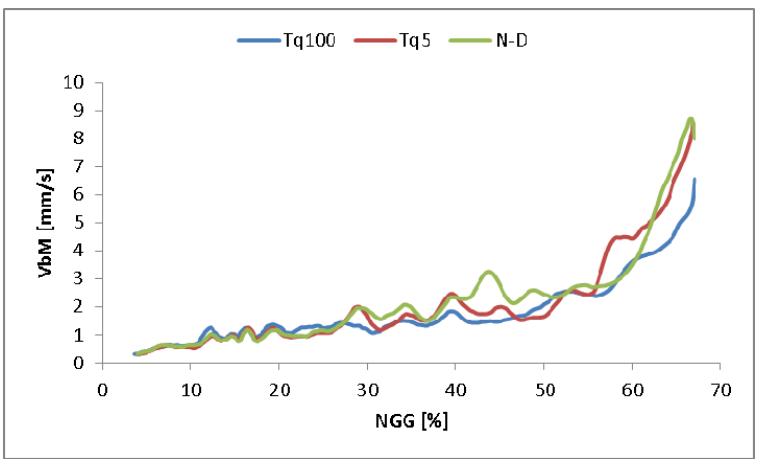

Fig. 14. Vibration variation with engine speed

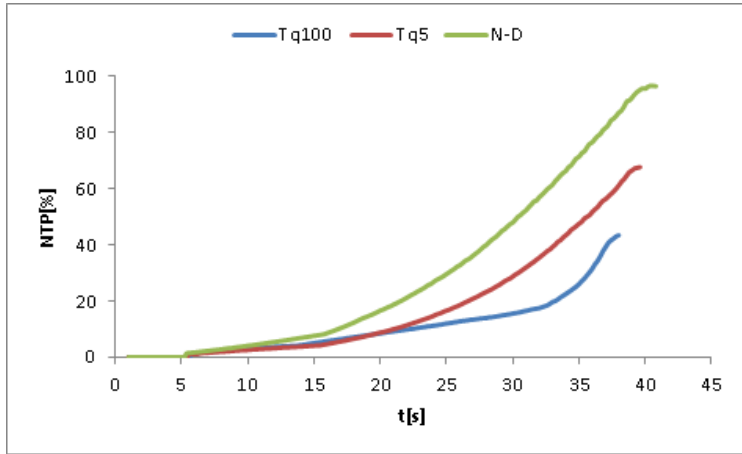

Fig. 15. Free turbine speed variation with starting time

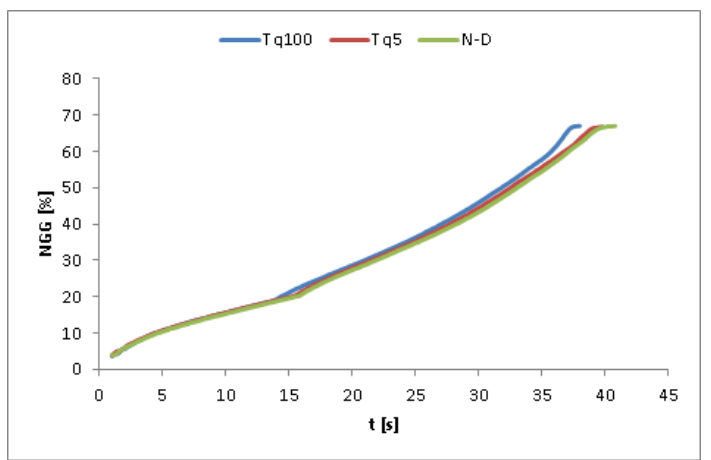

Fig. 16. Engine speed variation with starting time 


\section{CONCLUSIONS}

This paper presented a logic sequence procedure of engine starting, represented by a sequence diagram based on a general engine instrumentation scheme, in order to start up an engine which is not equipped with an electronic engine control. To perform a starting, into the test bench, the engine has an operating system composed of an acquisition system and a programmable logic controller connected with the engine and with the control panel. The paper examines two different types of starting and for that it was made a series of engine runs with different dynamometers loads, $5 \mathrm{Nm}$ and $100 \mathrm{Nm}$ torque values, and an engine run without load and dynamometer. In case of starting with the minimum load of $5 \mathrm{Nm}$ torque value, the free turbine speed is around $67 \%$ and the engine has a normal idle around $64 \%$. The engine obtained a power of $51 \mathrm{~kW}$. In case of normal starting with the helicopter load $\approx 100 \mathrm{Nm}$ torque value, the free turbine speed is around $45 \%$, the same as is specified in the engine book, the engine has a normal idle around $65 \%$ and obtained power of $61 \mathrm{~kW}$. In case of unusable starting with no load, the free turbine speed is around $93 \%$, and the engine has a normal idle around $65 \%$. The inlet turbine speed is higher for the higher load and lower for the unload starting. The static overall pressure ratio and air flow, has almost the same values and the same variation curves. The fuel flow is similar for load starting but for unload starting the fuel flow is lower than normal starting between $20 \div 30 \%$ of gas generator speed. The free turbine speed in higher for the unload starting and lower for the higher load. The difference between free turbine speeds is $20 \%$ higher for minimum load and $47 \%$ for the unload starting, than the normal starting. In case of vibrations the unload starting has somewhat higher values than the normal starting. The starting time is somehow similar, the unload starting and the minimum load starting has the starting time little bigger than normal starting. In conclusion the engine can be started load or unload, and results do not affect the gas generator idle but obtain different values of free turbine speed in function of load values.

\section{REFERENCES}

[1] W. Liou, C. Hoong Leong, "Gas Turbine Engine Testing Education, Western Michigan University", Collection of Technical Papers, 45th AIAA Aerospace Sciences Meeting, Vol. 13, pp. 8716-8724, 2007

[2] C. H. Leong, J., Jacob, W. W. Liou, "Development of a Turbojet Engine Lab For Propulsion Education", 40th AIAA/ASME/SAE/ASME Joint Propulsion Conference and Exhibit, AIAA paper 2004-4085, 2004

[3] TV2-117A Base Maintenance and Training Manual, Bucharest, 1973

[4] H Dumitrescu, Propeller Calculation, Publishing House Romanian Academy, Bucharest, 1990

[5] Federal Aviation Administration, Aviation Maintenance Technician Hand Book, Vol.1, FAA-H-8083-32

[6] Federal Aviation Administration, Aviation Maintenance Technician Hand Book, Vol.2, FAA-H-8083-32

[7] G. Cican, V. Stanciu, V. Silvestru, R. M. Catana, Fundamentals of Gas Turbine Engine Starting, Processes and Experiments, Printech, Bucharest, 2016 